\title{
Evaluation of Serum Testosterone, Progesterone, Seminal Antisperm Antibody, and Fructose Levels among Jordanian Males with a History of Infertility
}

\author{
Hala I. Al-Daghistani, ${ }^{1}$ Abdul-Wahab R. Hamad, ${ }^{2}$ Muna Abdel-Dayem, ${ }^{3}$ \\ Mohammad Al-Swaifi, ${ }^{3}$ and Mohammad Abu Zaid ${ }^{3}$ \\ ${ }^{1}$ Department of Medical Allied Sciences, Al-Salt University College, Al-Balqa Applied University, Al-Salt 19117, Jordan \\ ${ }^{2}$ Department of Medical Allied Sciences, Zarka University College, Al-Balqa Applied University, Zarka 13115, Jordan \\ ${ }^{3}$ Medical Hussein City Hospital, Amman 11855, Jordan
}

Correspondence should be addressed to Abdul-Wahab R. Hamad, wahabhamad2004@yahoo.com

Received 7 April 2010; Revised 23 May 2010; Accepted 19 October 2010

Academic Editor: T. B. Ng

Copyright (C) 2010 Hala I. Al-Daghistani et al. This is an open access article distributed under the Creative Commons Attribution License, which permits unrestricted use, distribution, and reproduction in any medium, provided the original work is properly cited.

\begin{abstract}
Due to the biochemical complexity of seminal fluid, we attempt to study the possible correlation between fructose, which is secreted under the effect of androgen hormone, and autoimmunity, which might play a role in varicocele associated infertility, in reducing sperm motility. Seminal fructose, antisperm antibodies (ASAs) and blood steroids hormones (testosterone and progesterone) levels were measured in 66 infertile males with varicocele and 84 without varicocele referred for fertility treatment. Seminal analysis was performed with biochemical measurements of seminal fructose and mixed agglutination reaction (MAR) for ASA. Serum levels of progesterone and testosterone were estimated using a competitive chemoluminescent enzyme immunoassay. The mean values for serum testosterone were $380.74 \pm 24.331,365.9 \pm 16.55$, and $367.5 \pm 21.8 \mathrm{ng} / \mathrm{dl}$, progesterone $0.325 \pm 0.243,0.341 \pm 0.022$, and $0.357 \pm 0.0306 \mathrm{ng} / \mathrm{ml}$, and seminal plasma fructose $359.6 \pm 26.75,315.6 \pm 13.08$, and $332.08 \pm 24.38 \mathrm{mg} / \mathrm{dl} \mathrm{in} \mathrm{males}$ with varicocele, without varicocele, and fertile males, respectively. A significant high level of testosterone was observed within varicocele group $(P=.001)$. This result showed that testosterone may play a role as an infertility determinant in subjects with varicocele. ASA was detected in $18(26.47 \%)$ of cases with varicocele, $20(38.46 \%)$ without varicocele, and in $16(32.0 \%)$ fertile men. Cases with ASAs associated with low sperm motility morphology. An inverse correlation between sperm-bound antibodies and viscosity has been shown $(P=.017)$. ASA showed some significant inverse relations with ages, durations of infertility, and viscosity $(P<.05)$. In addition, a significant correlation was observed between ASA positive seminal plasma and testosterone concentration among infertile cases (with or without varicocele) and fertile $(P<.05)$. Our results suggest a relationship between testicular steroid hormone levels with autoimmunity and sperm antibodies which influence the motility of ejaculated spermatozoa among Jordanian infertile males.
\end{abstract}

\section{Introduction}

Infertility is defined as inability of couples to achieve pregnancy following one year of unprotected intercourse. By this criterion, infertility affects $13 \%-18 \%$ of couples and male factors account for up to half of all cases [1]. One of male infertility causes is varicocele which is present in $2 \%$ $22 \%$ of the adult male population [2]. In men with abnormal semen analysis, the prevalence of varicocele reached $25 \%$ [3]. Cases of varicocele have been linked to a serious of events such as: biochemical changes in the epididymal fluid, a stasis of the internal spermatic vein, elevated scrotal temperature, testicular hypoxia, and retrograde blood flow of renal and adrenal metabolites [4]. Immunological and hormonal factors are vital factors responsible for reduction in sperm motility. They appeared to have certain role in varicocele-related infertility [5]. Data about their influence on seminal fluid parameters are contradictory, since males with varicocele showed infertility with variable semen finding. Moreover, some varicose males appeared fertile, 
but their fertility potential might decline gradually [6]. Hormonal imbalance and sperm autoimmunity have been considered as two systems that work in close association and affecting each other [7-9]. However, few studies revealed no correlation between autoimmunity and hormonal factor [10].

Autoantibodies to sperms are present approximately in $10 \%$ of infertile males [11] and in (24.6\% and 32\%) among patients with varicocele $[12,13]$. However, a number of investigators have found no association between ASA formation and varicocele $[14,15]$. ASA impair the fertilizing ability of spermatozoa by acting negatively on sperm motility and result in poor cervical mucus penetration and in vitro gamete interaction [16]. Sperm-bound antibodies have been found to impair sperm function only when the degree of antibody binding is very high $(>50 \%)$ [17].

Biochemical evaluation of seminal fluids suffering from varicocele provided some evidence on reduced fertility of their gametes. Any change in the biochemical composition of semen, such as reduced fructose levels, was known to cause a reduction in sperm motility [18]. Fructose is an important source of energy for the sperm. It is the principle source of the sperm motility under anaerobic conditions [19]. Lowered intensity of fructose oxidation in gamete mitochondria leads to accumulate lactate and inhibition of dehydrogenases activity [20]. This sugar has been studied extensively, because it is considered as a marker for seminal vesicle function [21]. Attempts to correlate fructose concentrations in seminal plasma with andrological parameters have produced inconsistent results. The content of fructose in fresh semen depends upon the secretion function of accessory glands which is influenced directly by the activity of the male sex hormone. The impaired sex accessory gland functions could arise from decreased venous drainage in the vesicoprostatic plexus. A low level of seminal fructose may coincide with other symptoms of hormonal malfunction and poor quality of spermatozoa. In varicocele, the impaired sex accessory gland secretions could themselves influence the motility of ejaculated spermatozoa [22]. However, other studies showed that seminal fructose did not have any statistically significant differences when comparing infertile patients with varicocele and fertile $[23,24]$.

Steroid hormones, such as testosterone, are necessary for the development and maintenance of secondary sexual characteristics as well as initiation and maintenance of spermatogenesis. It was known that males with varicocele and abnormal seminal fluids have lower concentrations of the testosterone hormone [25]. In addition, the secretion products of the secondary sex glands were more often in the lower range in the ejaculates of men combining varicocele with sexual disturbance, proving the decreased testosterone level to induce a deficient function of these glands [26]. Some relationships were also found between levels of testosterone and progesterone in the seminal plasma of semen samples with low sperm motility [7].

The impact of fructose, sperm autoantibodies, along with hormonal imbalance in the pathogenesis of varicocele is not known. In the present study, steroid hormones (testosterone and progesterone), ASA, and fructose were measured in serum and seminal plasma of infertile males with and without varicocele to study the possible correlation between the three parameters in reducing sperm motility.

\section{Materials and Methods}

2.1. Study Groups. One hundred and fifty infertile males (sixty eight $(34 \%)$ with varicocele and eighty two $(41 \%)$ without varicocele) were enrolled in the study with mean age of $31.87 \pm 0.468$ years and duration of infertility of $3.37 \pm 0.236$ years. Men were attending the infertility department at Medical Hussein City Hospital in Jordan, during December 2009 to January 2010 with complete medical and clinical histories. Patients were married and infertile (with their fertile female partner) for at least more than one year of unproductive intercourse. Varicocele was diagnosed after physical examination, duplex, and Color Doppler Ultrasonography. All cases of varicocele were classified as grade I (subclinical, audible, not visible, and not palpable) [27]. Control group consists of 50 (25\%) fertile married males with mean age $33.0 \pm 0.884$ years. They are clinically asymptomatic males without varicocele and normal seminal fluids. Informed consent was obtained from all study cases.

2.2. Seminal Fluid Samples. Semen samples were obtained by masturbation after 3-5 days of sexual abstinence and kept in sterile nontoxic recipients. Written and verbal advices were given to the patients to follow the procedure. Each patient provided at least two samples within one month. Samples were allowed to liquefy in the incubator directly and analyzed for sperm volume, concentration, $\mathrm{pH}$, viscosity, morphology, motility, and viability as indicated by the WHO manual for semen analysis [28]. Morphology was determined after incubation of the sample with trypsin for 10 minutes at $25^{\circ} \mathrm{C}$ according to the methylene blue eosin staining procedure, feathering, and fixation by flame. At least 100 cells were examined at a final magnification of 1000x. Viscosity of the liquefied sample was estimated by introducing a glass rod into the sample and observing the thread that forms on withdrawal of the rod. Threads obtained from normal samples should not exceed $2 \mathrm{~cm}$ in length [29]. Motility was expressed as a percentage of motile spermatozoa and their mean velocity. For the purpose of conventional analysis, a simple classification system is recommended in which a fixed volume of semen is delivered onto a clean glass slide and covered with a $22 \times 22 \mathrm{~mm}$ cover slip [28]. The preparation is then examined at a magnification of 400x. The microscopic field is scanned systematically, and the motility of each spermatozoon encountered is graded a, b, c, or d. At least 100 spermatozoa are classified in this way. The presence of $50 \%$ or more with forward progression (categories a and b) or $25 \%$ or more with rapid progression (category a) within 60 minutes of ejaculation were considered as normal results. The results were averaged for the two samples, and a single value was used for each parameter. Sperm motility was calculated by multiplying sperm concentration $(\mathrm{x} 10(6) / \mathrm{ml})$ and semen volume (ml). 
2.3. Mixed Antiglobulin Reaction (MAR) Test. The MAR test is performed by mixing fresh, untreated semen with sheep blood cells (SRBs) coated with human IgG. A monospecific antihuman- $\operatorname{IgG}$ antiserum is added to this mixture, which was mixed and read within 10 minutes. Positive and negative control samples were run along with each experiment. The formation of mixed agglutinates between sRBC and motile spermatozoa proves the presence of $\operatorname{IgG}$ antibodies on the sperms [30]. Immunologic infertility is suspected when $10 \%-90 \%$ of the motile spermatozoa attached to the RBCs.

2.4. Determination of Seminal Fluid Fructose. The method is adopted from that of Seliwanoff. The principle depends upon the presence of fructose (ketoses), which forms a pink color when heated with resorcinol in the presence of hydrochloric acid (ARCOMEX, Fructose. S.F). The intensity of the red complex is proportional to the fructose concentration and measured photometrically at $490 \mathrm{~nm}$ [31].

2.5. Hormone Estimation. Serum levels of progesterone and testosterone were estimated by a competitive chemoluminescent enzyme immunoassay using IMMULITE 2000 Progesterone and IMMULITE 2000 Total Testosterone which utilized specific antibody-coated polystyrene beads as a solid phase. [32, 33]. After the sample was incubated with alkaline phosphatase-labeled regent, the bound label was then quantified using a specific chemoluminescent substrate and light emission will be detected by photomultiplier tube, and the results were calculated for each samples. The normal ranges for progesterone is $0.27-0.9 \mathrm{ng} / \mathrm{ml}$ and for testosterone $262-1593 \mathrm{ng} / \mathrm{dl}$.

2.6. Statistical Analysis. SPSS software version 13.0 was used for data analysis. Results were presented as means value with deviations $( \pm$ SD). Significance of the differences was performed using $t$-test for equality of means, ANOVA correlation, descriptive, frequency, and chi-squared test. A $P$ value of $<.05$ was considered.

\section{Results}

3.1. Seminal Fluid Parameters. Serum and seminal plasma obtained from $68(34 \%)$ infertile males with varicocele and $82(41 \%)$ without varicocele, and $50(25 \%)$ fertile control males were investigated for the possible relations between fructose levels, steroid hormones, and autoimmunity to sperm antigens. Among the patients studied, the age varied from 25 to 47 years, thus covering the entire span of the reproductive years

Analyzing of seminal fluid samples revealed significant differences in sperm viability, motility, and morphology $(P \leq$ .05 ) among our study groups (Table 1 ).

3.2. Fructose and Sperm Antibodies. The level of fructose in the seminal plasma was (means \pm SD): $359.6 \pm 26.75$ (range, 102-1038), 315.6 \pm 13.08 (range, 35-671), and 332.08 \pm 24.38 (range, 113-909) $\mathrm{mg} / \mathrm{dl}$ in males with varicocele, without varicocele, and fertile males, respectively. The level of seminal

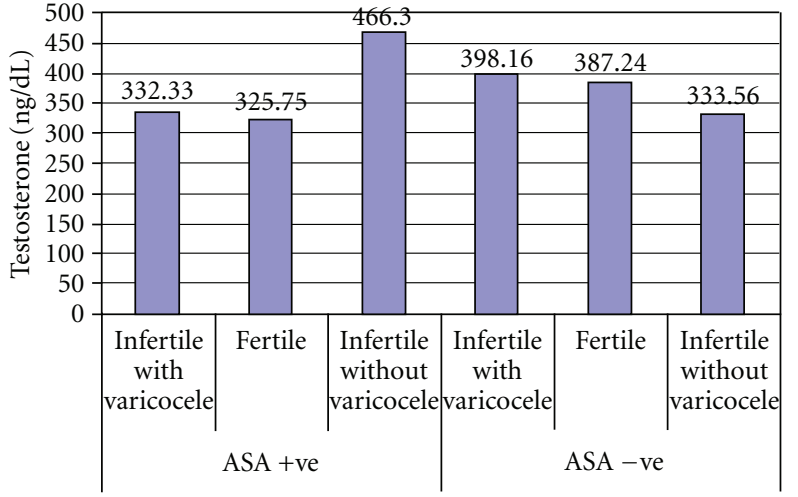

FIgUre 1: Testosterone levels in the serum of infertile and fertile men in relation to sperm antibodies.

fructose among infertile groups (with or without varicocele) was found to be slightly higher than fertile, without being statistically significant.

3.3. Antisperm Autoantibodies (ASAs). Mixed Antiglobulin reaction test was used for sperm antibodies in the seminal plasma. ASA was detected in $18(26.47 \%)$ male with varicocele, $20(38.46 \%)$ without varicocele, and in $16(32 \%)$ fertile males. Most of tested samples showed $\geq 40 \%$ of the motile sperm which have been attached to RBCs. No significant difference in ASA was recorded between males with varicocele and other without in comparison to fertile males. ASA showed some significant inverse relation with ages, durations of infertility, and viscosity $(P<.05)$. Most semen samples positive for ASA 50 (92.6\%) showed normal viscosity, while only $4(7.4 \%)$ semen with autoantibodies appeared viscous (Table 2).

3.4. Steroid Hormone. The mean values for serum testosterone and progesterone were: (means \pm SD) $380.74 \pm 200.6$ (range, 140-1342), $365.9 \pm 149.9$ (range, 173-903), and $367.5 \pm 154.2$ (range, 42-788) ng/dl for testosterone, while $0.325 \pm 0.200$ (range, 0.15-0.86), $0.357 \pm 0.216$ (range, $0.15-1.10$ ), and $0.341 \pm 0.208$ (range, $0.09-0.89) \mathrm{ng} / \mathrm{ml}$ for progesterone in males with varicocele, without varicocele, and fertile males, respectively (Table 1 ). The levels of progesterone was found to increase with ages $(P=.007)$. Correlation results revealed a significant difference in testosterone concentration between infertile and fertile group $(P=.047)$, with the highest level in males with varicocele (Figures 2, 3, and 4). Progesterone level was found to have a direct significant relation to the serum level of testosterone $(P=.008)$. Analysis of variants showed a significant correlation between antibodies to sperm present in the seminal fluids of infertile and fertile men and steroid levels such as testosterone in their serum $(P<.05)$ (Figure 1).

\section{Discussion}

It has been found that prostate and vesicle infection and subclinical reproductive tract infection may lead to dysfunction 
TABle 1: A comparison between Sperm parameters, fructose level, steroid hormones among infertile males with varicocele, without varicocele, and fertile.

\begin{tabular}{|c|c|c|c|c|}
\hline \multirow{4}{*}{ Parameters } & \multirow{4}{*}{$\begin{array}{l}\text { Fertile group } \\
\qquad \begin{array}{c}\text { No }=50 \\
\text { Means } \pm \text { SD }\end{array}\end{array}$} & \multicolumn{2}{|c|}{ Infertile group } & \multirow{4}{*}{$P$-value } \\
\hline & & Varicocele & Without varicocele & \\
\hline & & No. 68 & No. 82 & \\
\hline & & Means \pm SD & Means \pm SD & \\
\hline Volume (ml) & $3.54 \pm 1.77$ & $4.06 \pm 1.92$ & $3.90 \pm 2.26$ & n.s \\
\hline Count $10(6) / \mathrm{ml}$ & $42.10 \pm 22.3$ & $55.03 \pm 77.62$ & $36.63 \pm 49.29$ & n.s \\
\hline Viscosity & $0.16 \pm 0.37$ & $0.21 \pm 0.41$ & $0.20 \pm 0.46$ & n.s \\
\hline \multicolumn{5}{|l|}{ Morphology } \\
\hline Normal shape & $8.12 \pm 8.75$ & $6.91 \pm 6.58$ & $7.46 \pm 7.92$ & * \\
\hline Slightly abnormal & $16.48 \pm 12.09$ & $21.35 \pm 11.09$ & $17.63 \pm 1284$ & * \\
\hline Coiled & $19.20 \pm 17.96$ & $13.71 \pm 10.53$ & $7.93 \pm 7.65$ & * \\
\hline Severe abnormal & $56.28 \pm 20.24$ & $52.15 \pm 20.79$ & $53.36 \pm 27.25$ & n.s \\
\hline \multicolumn{5}{|l|}{ Motility } \\
\hline Active progressive & $8.52 \pm 14.09$ & $5.26 \pm 13.28$ & $3.05 \pm 7.50$ & * \\
\hline Weak progressive & $12.76 \pm 11.17$ & $8.82 \pm 12.67$ & $7.88 \pm 10.41$ & * \\
\hline Sluggish & $28.56 \pm 117.02$ & $35.71 \pm 121.94$ & $34.71 \pm 126.54$ & n.s \\
\hline Immotile & $50.48 \pm 19.36$ & $44.56 \pm 23.55$ & $40.26 \pm 28.29$ & n.s \\
\hline Viability & $50.48 \pm 19.36$ & $44.56 \pm 23.55$ & $40.26 \pm 28.29$ & $*$ \\
\hline Fructose mg/dl & $332.08 \pm 172.43$ & $359.65 \pm 220.64$ & $315.66 \pm 118.49$ & n.s \\
\hline Testosterone ng/dl & $367.5 \pm 21.8$ & $380.74 \pm 24.331$ & $365.9 \pm 16.55$ & $*$ \\
\hline Progesterone ng/ml & $0.357 \pm 0.0306$ & $0.325 \pm 0.243$ & $0.341 \pm 0.022$ & n.s \\
\hline
\end{tabular}

${ }^{*} P \leq .05$ (Significant)

n.s (Non-Significant)

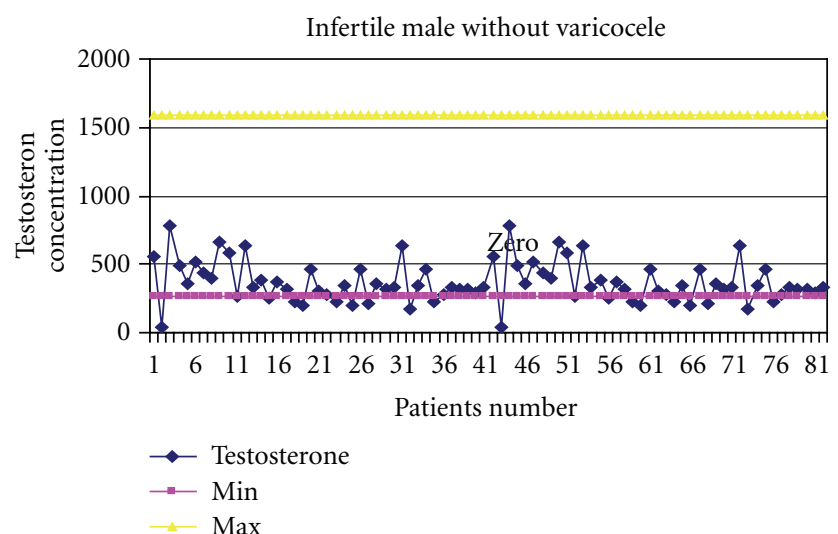

FIGURE 2: Ranges of testosterone concentration in the serum of infertile males without varicocele.

of sperm and changes in semen parameters, and the latter may consequently lead to infertility. Some possible pathophysiological mechanisms of the development of infertility are linked either to inhibition of spermatogenesis resulting from testicular damage or autoimmune process [34, 35]. Varicocele is the most common cause of male infertility and its pathophysiology is multifactorial.

Two hundred Jordanian males form in this study under investigation. The number of patients aged between 25 to 45 years was very high. This might be due to the fact that in our society, the majority of marriages take place in this age

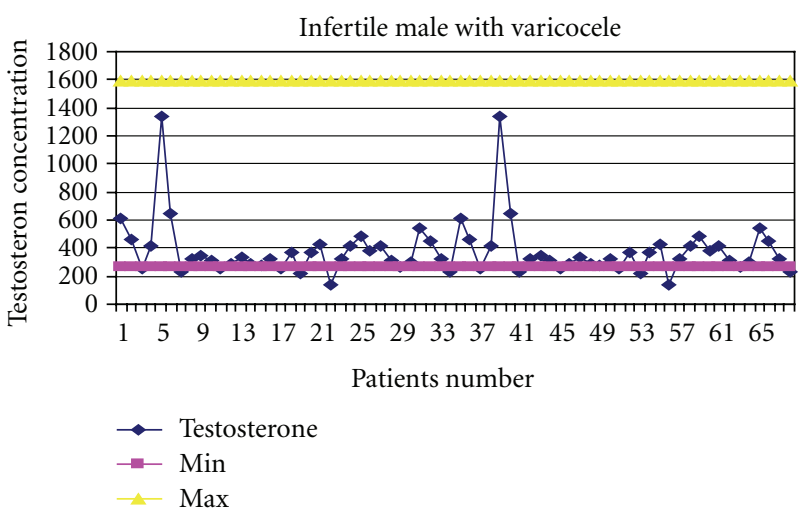

FIGURE 3: Range of testosterone concentrations in the serum of infertile males with varicocele.

group. The least number of cases were seen in age groups 47 and beyond, as late marriages are not common in our society.

The function of sex accessory glands in infertile males and fertile males was investigated by determining fructose levels in the seminal fluids. Regarding fructose estimation, it was noted from this study that fructose concentration did not differ significantly between the whole infertile group and the fertile group, beside that, there was no significance difference between the varicocele and without varicocele groups within the infertile group. This result is in accordance with the studies below that indicate the measurement of seminal fluid 


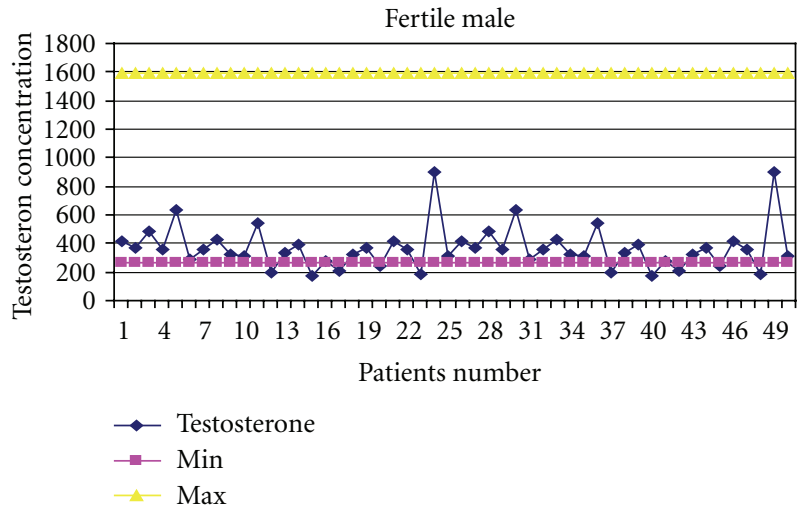

FIgURE 4: Ranges of testosterone concentration in the serum of fertile males.

fructose does not contribute to the diagnosis of infertility or infection, because its discriminating power is lower than that of the ejaculate volume which is equally dependent on seminal vesicle function $[36,37]$. The relationship between seminal fructose concentration and sperm characteristics was investigated in semen of 150 infertile men without evidence of disturbances in the seminal function. The result of this study is in accordance with other studies which pointed out that seminal fructose levels did not reflect the extension of prostate vesiculoepididymitis [38]. It is concluded that seminal fructose levels detected in the routine of semen analysis give no information on the clinical usefulness in defective sperm formation [36]. Therefore, in conclusion, estimation of seminal fructose fluid is not an efficient marker for the fertility.

Sperm density, viability, $\mathrm{pH}$, motility (active progressive, weak progressive, sluggish, and immotile), morphology (normal shape, oval, coiled, round-head, double-head, pinhead, tapering, mid-piece defects, small, large, tail defects, and combined defects), leukocytes, viscosity, immature germ cells, and sperm autoantibodies were assessed in different levels of seminal fructose, testosterone, and progesterone concentrations, as shown in Table 1. However, none of the sperm characteristics analyzed had shown statistically significant differences among the study groups. It is concluded that seminal fructose levels detected in the routine of semen analysis give no information on the clinical usefulness in defective sperm formation.

One of the hormonal measurements in infertile males, both from the diagnostic and prognostic point of view, is the steroid hormones. In the present study, it has been observed that in most cases, there was an extraordinary increase in the levels of testosterone and progesterone, which might be the cause of fertile males. This argument is in agreement with an earlier study [39], in which it was reported that androgen production by the prostate may be markedly increased in some normal states, usually correlated with fertility. Upon the basis of the findings generated from the study, it can be safely concluded that elevated testosterone levels are indeed significantly responsible for fertility in men, as they were observed in more than one-third of the studied cases. Although some studies have claimed that serum testosterone levels demonstrate no relationship to sperm concentration or testicular biopsy [40,41], others suggest that testosterone may assume a critical role in both the morphological development and reproductive function in males $[42,43]$. Infertile patients without varicocele show very low levels of serum testosterone, as compared to patients with varicocele which appeared statistically significant. Their tissues may indicate severe seminiferous tubule atrophy, sclerosis, and Leydig cell hyperplasia. These findings imply that testosterone levels may predict whether normal spermatogenesis is occurring within the seminiferous tubules of infertile patients. However, testosterone elevation was not found to be age dependent. Since testosterone elevation always has severe indirect effects, it is suggested that in order to encounter the type of infertility this hormone causes, special efforts should be made to pinpoint the disturbance that actually is the cause of elevation in this hormone for the particular patient.

Antisperm antibodies impair a man's fertility potential primarily by impairing sperm transport through the female reproductive tract. This immunologic factor was diagnosed when $10 \%-90 \%$ of motile sperms were attached to RBCs (Table 1). In this study, the prevalence of ASA among infertile males with varicocele was found to be lower than males without varicocele and corresponds to the expected prevalences present in other studies $[12,44]$. These results postulated that the presence of ASA is of a little relevance in varicocele-associated infertility. However, data about the influence of varicocele on ASA formation are contradictory. Surgical correction of varicocele did not show any significant differences in semen parameters in men with or without ASA [45]. Although $50 \%$ of men with clinically palpable varicoceles were documented to have positive ASA [46], but the clinical significant of ASA is low and does not influence infertility prognosis [47]. Theoretically, in patients with varicocele, the testes suffers deleterious tissue effect which sometimes leads to a complete atrophy that attributed to the prolonged venous stasis and hyperthermia and might induce antibody formation [48]. In addition, reduced Ecadherin and $\alpha$-catenin expression at the junctions between adjacent Sertoli cells in varicocele cases might also lead to a disruption of blood-testis barrier and the production of antibodies [49]. The debate over ASA and varicocele will continue as a number of questions remain to be answered, such as the exact role of ASA in infertility, which method of ASA testing is optimal for screening and final determination, what threshold levels of ASA are significant, which part on spermatozoa are involved in binding, how ASA interfere with the different steps in fertilization process, and what is the best method used for treatment of cases with ASAs-related infertility.

ASA showed some significant inverse relation with ages, durations of infertility, and viscosity. The importance of semen viscosity lies in the fact that the spermatozoa are tangled in the mucoid mass in the semen and prevented from migrating into the cervical tract to ascend to the site of fertilization. Seminal viscopathy was shown to be associated with male infertility [50]. We investigated the 
TABLE 2: Relationship between autoantisperm antibodies and sperm viscosity.

\begin{tabular}{lccc}
\hline Sperm viscosity & Antisperm antibodies & & Total \\
& ASA negative & ASA positive & $164(82 \%)$ \\
Normal viscosity & $114(57 \%)$ & $50(25 \%)$ & $34(17 \%)$ \\
Viscous semen & $30(15 \%)$ & $4(2 \%)$ & $2(2 \%)$ \\
Highly viscous & $2(1 \%)$ & $0(0 \%)$ & $2 \%$ \\
\hline
\end{tabular}

relations between semen viscosity and the presence of ASA (Table 2). A significant inverse relation between ASA and semen viscosity was revealed, and semen with ASA showed normal viscosity. This finding was not in agreement with other studies which cited to the correlation of ASA and semen hyperviscosity [51]. Local ASA stimulate interferon $\gamma$ production, which plays, a role in enhancing directly phagocytic cells to produce hydrolyase, lipase, and esterase and indirectly by phosphor elation of proteins through activation of certain enzymes such as protein kinase. All these events participate in liquefying viscous semen and allowed it to appear with normal viscosity [52].

A significant correlation was observed between ASA and testosterone levels among study cases. This fact was clarified in Figure 1, in which testosterone level among infertile males without varicocele and positive for ASA was shown to be significantly higher than its level present in varicose infertile and fertile males. This is due to the risk factors for developing antisperm antibodies including a history of testicular injury, torsion, vasectomy/reversal, or infection. Alteration of steroid hormone levels such as testosterone in the seminal plasma of males with ASA has been mentioned in certain articles which suggest a relationship between testicular steroid hormone levels and autoimmunity to sperm antibodies [7]. Exogenous administration of estradiol in the rats significantly increased the IgA and IgG type of antibodies in the uterus, suggesting estradiol-dependent development of specific antibodies in the genital tract [53]. Steroids, such as estrogen and progesterone, are known to regulate lymphocyte proliferation through cytokine action [54] and participate in humoral immune responses by modulating antibody synthesis [55]. Thus, it could be said that higher testosterone levels may be responsible for higher levels of antibodies in the seminal fluids which might ultimately inhibit the motility of spermatozoa. We can concluded that high levels of testosterone stimulate the humoral immune response, and hence ASA production which causes a reduction in sperm motility.

Due to the significance of testosterone hormone in relation to males' infertility, it should invariably become a regular part of the hormonal profile recommended for men undergoing fertility assessment. Seminal fructose may not contribute to fertility through its effect on various semen parameters.

\section{Acknowledgments}

The authors are grateful and express their appreciation to AlBalqa Applied University, Zarka University College, Al-Salt
University College, and Medical Hussein City, Amman, for facilitating and supporting this research. They express a lot of appreciation to Mr. Mohammad Khalaf for his assistance in statistical analysis.

\section{References}

[1] E. Iammarrone, R. Balet, A. M. Lower, C. Gillott, and J. G. Grudzinskas, "Male infertility," Best Practice and Research, vol. 17, no. 2, pp. 211-229, 2003.

[2] E. D. Kursh, "What is the incidence of varicocele in a fertile population?" Fertility and Sterility, vol. 48, no. 3, pp. 510-511, 1987.

[3] S. A. Said, A. Aribarg, P. Virutamsen et al., "The influence of varicocele on parameters of fertility in a large group of men presenting to infertility clinics," Fertility and Sterility, vol. 57, no. 6, pp. 1289-1293, 1992.

[4] V. Ficarra, A. B. Porcaro, R. Righetti et al., "Antegrade scrotal sclerotherapy in the treatment of varicocele: a prospective study," British Journal of Urology International, vol. 89, no. 3, pp. 264-268, 2002.

[5] J. Golomb, N. Vardinon, and Z. T. Homonnai, "Demonstration of antispermatozoal antibodies in varicocele-related infertility with an enzyme-linked immunosorbent assay (ELISA)," Fertility and Sterility, vol. 45, no. 3, pp. 397-402, 1986.

[6] F. F. Pasqualotto, A. Sundaram, R. K. Sharma, E. Borges Jr., E. B. Pasqualotto, and A. Agarwal, "Semen quality and oxidative stress scores in fertile and infertile patients with varicocele," Fertility and Sterility, vol. 89, no. 3, pp. 602-607, 2008.

[7] R. Kiran and T. G. Shrivastav, "A correlation study between steroid hormone levels and anti-sperm antibodies in serum and seminal plasma of men with or without reduced sperm motility," Journal of Endocrinology and Reproduction, vol. 1, pp. 31-35, 2007.

[8] A. Basu, S. Nara, S. K. Chaube, K. Rangari, K. P. Kariya, and T. G. Shrivastav, "The influence of spacer-containing enzyme conjugate on the sensitivity and specificity of enzyme immunoassays for hapten," Clinica Chimica Acta, vol. 366, no. 1-2, pp. 287-292, 2006.

[9] W. Kiess and B. H. Belohradsky, "Endocrine regulation of the immune system," Klinische Wochenschrift, vol. 64, no. 1, pp. $1-7,1986$.

[10] V. A. Bozhedomov and O. V. Teodorovich, "Epidemiology and causes of autoimmune male infertility," Urologiia, no. 1, pp. 35-44, 2005.

[11] ESHRE Capri Workshop, "Male infertility update," Human Reproduction, vol. 13, no. 7, pp. 2025-2032, 1998.

[12] H. Özen, G. Asar, S. Güngör, and A. F. Peker, "Varicocele and antisperm antibodies," International Urology and Nephrology, vol. 17, no. 1, pp. 97-101, 1985. 
[13] B. R. Gilbert, S. S. Witkin, and M. Goldstein, "Correlation of sperm-bound immunoglobulins with impaired semen analysis in infertile men with varicoceles," Fertility and Sterility, vol. 52, no. 3, pp. 469-473, 1989.

[14] E. Veräjänkorva, M. Laato, and P. Pöllänen, “Analysis of 508 infertile male patients in south-western Finland in 1980-2000: hormonal status and factors predisposing to immunological infertility," European Journal of Obstetrics Gynecology and Reproductive Biology, vol. 111, no. 2, pp. 173-178, 2003.

[15] G. S. Oshinsky, M. V. Rodriguez, and B. C. Mellinger, "Varicocele-related infertility is not associated with increased sperm- bound antibody," Journal of Urology, vol. 150, no. 3, pp. 871-873, 1993.

[16] F. Lombardo, L. Gandini, A. Lenzi, and F. Dondero, "Antisperm immunity in assisted reproduction," Journal of Reproductive Immunology, vol. 62, no. 1-2, pp. 101-109, 2004.

[17] C. L. R. Barratt, B. C. Dunphy, I. McLeod, and I. D. Cooke, "The poor prognostic value of low to moderate levels of sperm surface-bound antibodies," Human Reproduction, vol. 7, no. 1, pp. 95-98, 1992.

[18] G. F. Gonzales and A. Villena, "True corrected seminal fructose level: a better marker of the function of seminal vesicles in infertile men," International Journal of Andrology, vol. 24, no. 5, pp. 255-260, 2001.

[19] W. M. Buckett and D. I. Lewis-Jones, "Fructose concentrations in seminal plasma from men with nonobstructive azoospermia," Archives of Andrology, vol. 48, no. 1, pp. 23-27, 2002.

[20] S. B. Artifeksov, "The biochemical characteristics of the sperm in patients with varicocele," Urologiya i Nefrologiya, no. 5, pp. 50-52, 1991.

[21] T. T. Ndovi, L. Choi, B. Caffo et al., "Quantitative assessment of seminal vesicle and prostate drug concentrations by use of a noninvasive method," Clinical Pharmacology and Therapeutics, vol. 80, no. 2, pp. 146-158, 2006.

[22] S. Andò, A. Carpino, M. Buffone, M. Maggiolini, C. Giacchetto, and F. Seidita, "Fructose, prostatic acid phosphatase and zinc levels in the seminal plasma of varicoceles," International Journal of Fertility, vol. 35, no. 4, pp. 249-252, 1990.

[23] K. H. Park and H. Y. Lee, "Studies on seminal fructose, plasma testosterone, follicle-stimulating hormone and luteinizing hormone," Korean Journal of Urology, vol. 20, no. 1, pp. 3147, 1979.

[24] N. Rodrigues-Netto Jr. and M. P. P. De Castro, "Hormonal and biochemical parameters in varicocele," International Journal of Fertility, vol. 25, no. 4, pp. 311-314, 1980.

[25] T. Ishikawa and M. Fujisawa, "Varicocele ligation on free testosterone levels in infertile men with varicocele," Archives of Andrology, vol. 50, no. 6, pp. 443-448, 2004.

[26] F. Comhaire and A. Vermeulen, "Plasma testosterone in patients with varicocele and sexual inadequacy," Journal of Clinical Endocrinology and Metabolism, vol. 40, no. 5, pp. 824829, 1975.

[27] M. Yamamoto, H. Hibi, Y. Hirata, K. Miyake, and T. Ishigaki, "Effect of varicocelectomy on sperm parameters and pregnancy rate in patients with subclinical varicocele: a randomized prospective controlled study," Journal of Urology, vol. 155 , no. 5, pp. 1636-1638, 1996.

[28] World Health Organization, WHO Laboratory Manual for the Examination of Human Semen and Semen-Cervical Mucus Interaction, Cambridge University Press, Cambridge, UK, 3rd edition, 1992.

[29] F. Comhaire and L. Vermeulen, "Human semen analysis," Human Reproduction Update, vol. 1, no. 4, pp. 343-362, 1995.
[30] W. F. Hendry, J. Stedronska, and R. A. Lake, "Mixed erythrocyte-spermatozoa antiglobulin reaction (MAR test) for IgA antisperm antibodies in subfertile males," Fertility and Sterility, vol. 37, no. 1, pp. 108-112, 1982.

[31] T. Mant, "Fructose content and fructolysis in semen. Practical application in the evaluation of semen quality," The Journal of Agricultural Science, vol. 38, p. 323, 1948.

[32] L. Vankrieken, "IMMULITE reproductive hormone assays: multicenter reference range data," Document zb157-D, Diagnostic Products Corporation, Los Angeles, Calif, USA, 2000.

[33] G. E. Abraham, Ed., Handbook of Radioimmunoassay, Marcel Dekker, New York, NY, USA, 1977.

[34] O. V. Bukharin, M. D. Kuz'min, and I. B. Ivanov, "The role of the microbial factor in the pathogenesis of male infertility," Zhurnal Mikrobiologii Epidemiologii i Immunobiologii, no. 2, pp. 106-110, 2000.

[35] M. Huerta, R. C. Aguilar, I. Hernández, and A. R. Ayala, "Frequency and etiology of seminal infection in the study of infertile couples," Ginecologia y Obstetricia de Mexico, vol. 70, pp. 90-94, 2003.

[36] F. T. Andrade-Rocha, "Seminal fructose levels in male infertility: relationship with sperm characteristics," International Urology and Nephrology, vol. 31, no. 1, pp. 107-111, 1999.

[37] G. Grizard, L. Janny, and J. Hermabessiere, "Seminal biochemistry and sperm characteristics in infertile men with bacteria in ejaculate," Archives of Andrology, vol. 15, no. 2-3, pp. 181-186, 1985.

[38] E. Vicari, S. La Vignera, R. Castiglione, and A. E. Calogero, "Sperm parameter abnormalities, low seminal fructose and reactive oxygen species overproduction do not discriminate patients with unilateral or bilateral post-infectious inflammatory prostato-vesiculo-epididymitis," Journal of Endocrinological Investigation, vol. 29, no. 1, pp. 18-25, 2006.

[39] E. F.-E. Omer, "Inflammatory conditions and semen quality among subfertile Sudanese males," Tropical Doctor, vol. 15, no. 1, pp. 27-28, 1985.

[40] R. Jackaman, R. Ghanadian, and I. D. Ansell, "Relationships between spermatogenesis and serum hormone levels in subfertile men," British Journal of Obstetrics and Gynaecology, vol. 84, no. 9, pp. 692-696, 1977.

[41] D. G. Goulis, C. Tsametis, P. K. Iliadou et al., "Serum inhibin $\mathrm{B}$ and anti-Müllerian hormone are not superior to folliclestimulating hormone as predictors of the presence of sperm in testicular fine-needle aspiration in men with azoospermia," Fertility and Sterility, vol. 91, no. 4, pp. 1279-1284, 2009.

[42] R. W. Holdcraft and R. E. Braun, "Hormonal regulation of spermatogenesis," International Journal of Andrology, vol. 27, no. 6, pp. 335-342, 2004.

[43] S. Takada, A. Tsujimura, T. Ueda et al., "Androgen decline in patients with nonobstructive azoospemia after microdissection testicular sperm extraction," Urology, vol. 72, no. 1, pp. 114-118, 2008.

[44] B. R. Gilbert, S. S. Witkin, and M. Goldstein, "Correlation of sperm-bound immunoglobulins with impaired semen analysis in infertile men with varicoceles," Fertility and Sterility, vol. 52, no. 3, pp. 469-473, 1989.

[45] G. Knudson, L. Ross, D. Stuhldreher, D. Houlihan, E. Bruns, and G. Prins, "Prevalence of sperm bound antibodies in infertile men with varicocele: the effect of varicocele ligation on antibody levels and semen response," Journal of Urology, vol. 151, no. 5, pp. 1260-1262, 1994.

[46] G. Isitmangil, S. Yildirim, I. Orhan, A. Kadioğlu, and M. Akinci, "A comparison of the sperm mixed-agglutination 
reaction test with the peroxidase-labelled protein A test for detecting antisperm antibodies in infertile men with varicocele," British Journal of Urology International, vol. 84, no. 7, pp. 835-838, 1999.

[47] W. Eggert-Kruse, M. Christmann, I. Gerhard, S. Pohl, K. Klinga, and B. Runnebaum, "Circulating antisperm antibodies and fertility prognosis: a prospective study," Human Reproduction, vol. 4, no. 5, pp. 513-520, 1989.

[48] A. El-Gendy, I. Younis, A. A. El-Taweel, and Y. Megahed, "Antisperm antibodies in varicocele related infertility," Medical Journal of Cairo University, vol. 62, no. 1, pp. 189-193, 1994.

[49] I. T. Koksal, Y. Ishak, M. Usta et al., "Varicocele-induced testicular dysfunction may be associated with disruption of blood-testis barrier," Archives of Andrology, vol. 53, no. 1, pp. 43-48, 2007.

[50] K. Gopalkrishnan, V. Padwal, and D. Balaiah, "Dose seminal fluid viscosity influence sperm chromatin integrity," Systems Biology in Reproductive Medicine, vol. 45, no. 2, pp. 99-103, 2000.

[51] A. Emin, E. Konova, D. Lichev et al., "The importance of the presence of antisperm antibodies in serum and ejaculate of men with infertility," Akusherstvo i Ginekologiia, vol. 47, no. 2, pp. 26-30, 2008.

[52] J. J. Oppendeim, F. W. Ruscett, and C. R. Faltunek, "Interleukins and interferon," in Basic and Clinical Immunology, D. P. Stites, J. D. Stobo, and J. V. Well, Eds., pp. 82-95, Lange Medical Book, 6th edition, 1987.

[53] C. R. Wira and J. Stern, "Endocrine regulation of the mucosal immune system in the female reproductive tract: control of IgA, IgG and secretory component during the reproductive cycle, on implantation and throughout pregnancy," in Hormones and Foetal Patho-Physiology, J. R. Pasqualini and R. Scholler, Eds., pp. 343-367, Marcel Decker, New York, NY, USA, 1991.

[54] S. P. Grekova, M. A. Vodyanik, and V. P. Chernyshov, "The effect of progesterone and estrogen on proinflammatory cytokine co-stimulatory proliferative activity," American Journal of Reproductive Immunology, vol. 48, p. 147, 2002.

[55] A. Canellada, S. Blois, T. Gentile, and R. A. Margni Idehu, "In vitro modulation of protective antibody responses by estrogen, progesterone and interleukin-6," American Journal of Reproductive Immunology, vol. 48, no. 5, pp. 334-343, 2002. 

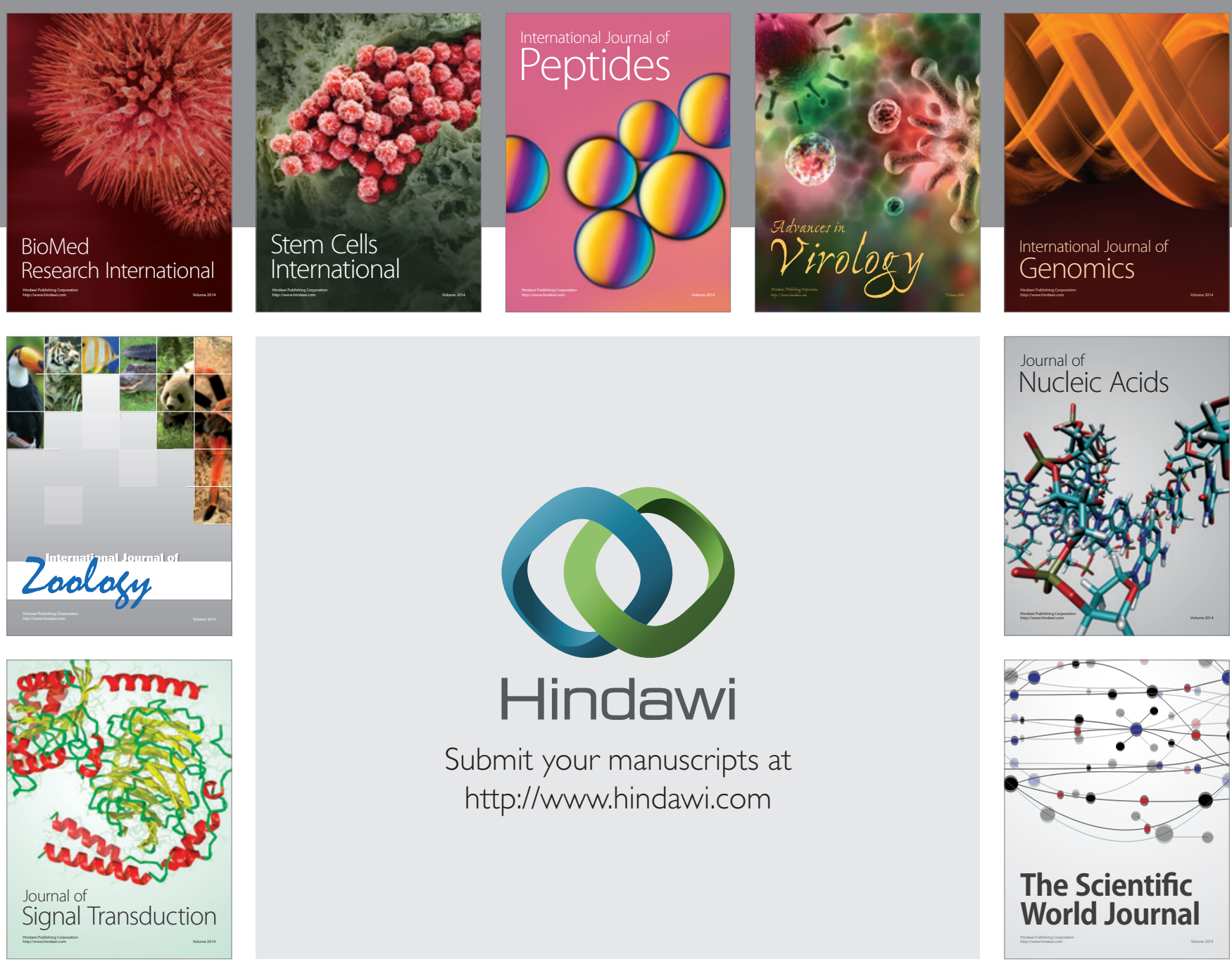

Submit your manuscripts at

http://www.hindawi.com
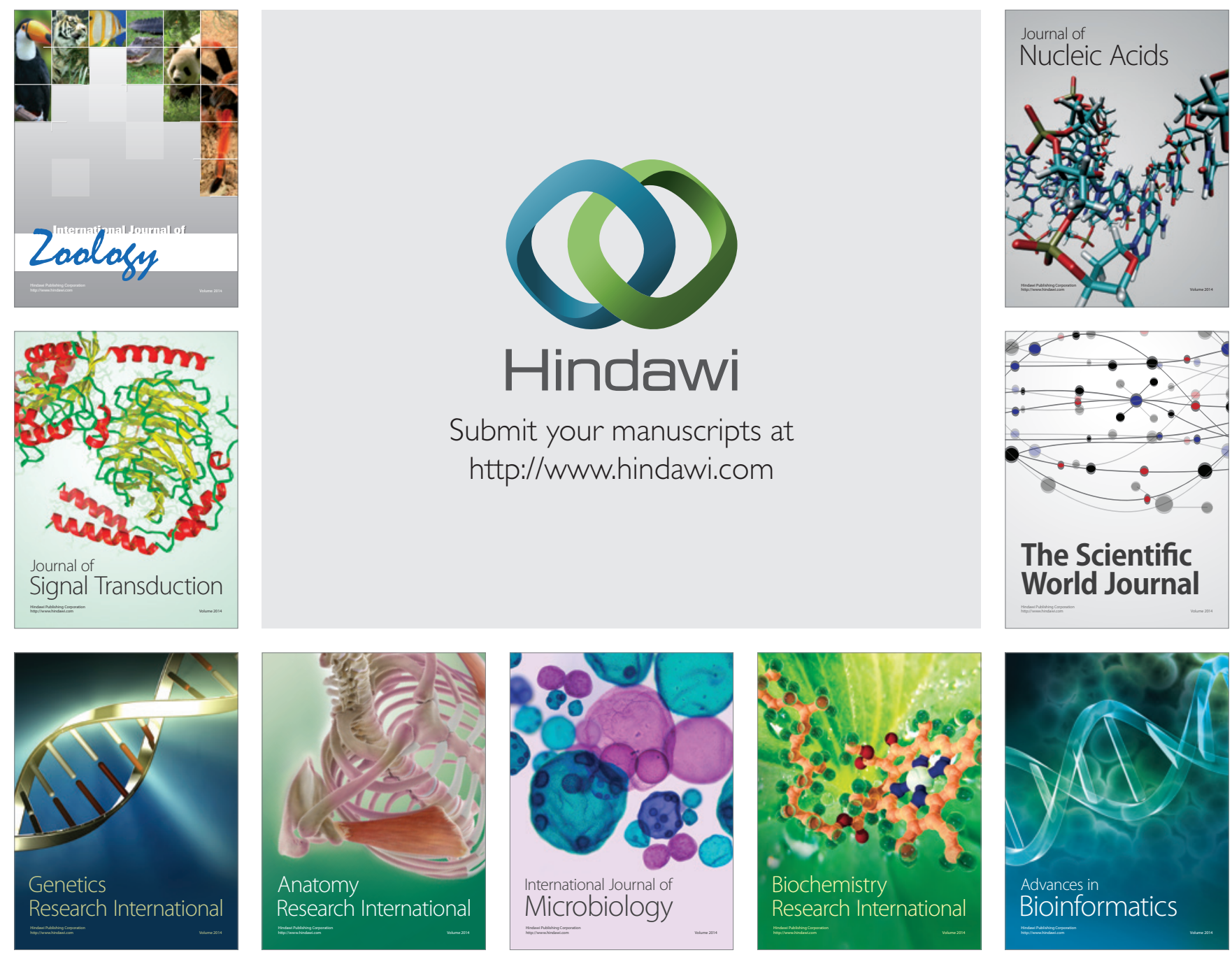

The Scientific World Journal
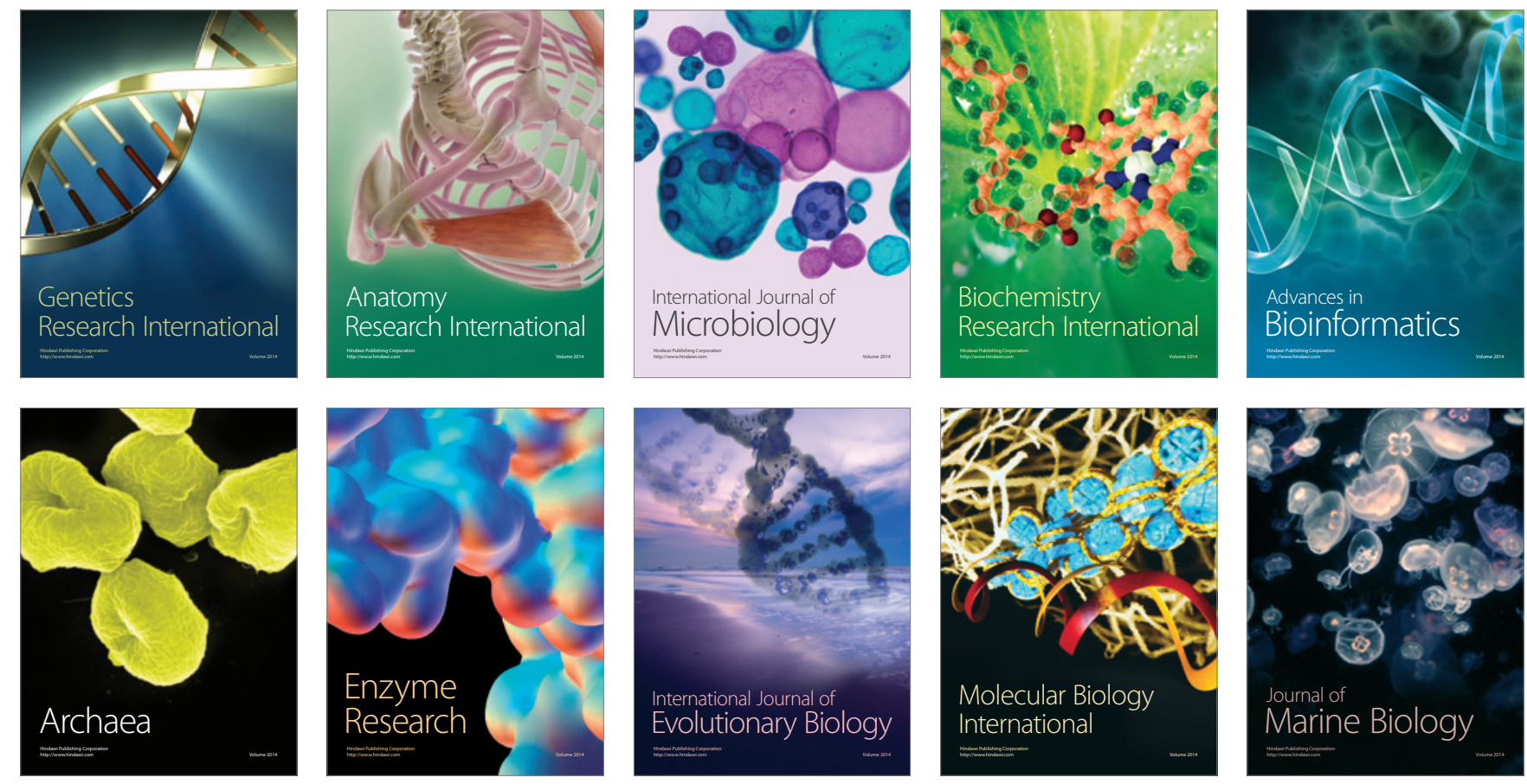